\title{
Supercritical Fluid Extraction of Oil from Sweet Flag Rhizome (Acorus calamus L.) and Its Insecticidal Activity on Pulse Beetles (Callosobruchus maculatus)
}

\author{
Shreelaxmi ${ }^{* *}$, H. Sharanagouda ${ }^{1}$, C.T. Ramachandra ${ }^{1}$, R.S. Roopa ${ }^{1}$ and S.G. Hanchinal ${ }^{2}$ \\ ${ }^{1}$ Department of Processing and Food Engineering, College of Agricultural Engineering, \\ University of Agricultural Sciences, Raichur-584102, Karnataka, India \\ ${ }^{2}$ Department of Entomology, College of Agriculture, University of Agricultural Sciences, \\ Raichur- 584 102, Karnataka, India \\ *Corresponding author
}

\section{A B S T R A C T}

\begin{tabular}{|l|}
\hline Ke y w o r d s \\
Supercritical fluid, \\
$\begin{array}{l}\beta \text {-asarone, sweet } \\
\text { flag rhizome, } \\
\text { insecticides, } \\
\mathrm{SC}^{-\mathrm{CO}_{2}}\end{array}$ \\
\hline Article Info \\
\hline $\begin{array}{l}\text { Accepted: } \\
\text { xx August } 2017 \\
\text { Available Online: } \\
\text { xx October } 2017\end{array}$ \\
\hline
\end{tabular}

\section{Keywords}

\section{Introduction}

Sweet flag (Acorus calamus) belongs to family Acoraceae comprises about 110 genera and more than 1800 species. The genus name, Acorus is derived from Acoron (coreon $=$ the pupil of the eye) and the species calamus is derived from the Greek word, Calamus (a reed). The members of the family are rhizomatous or tuberous herbs. The genus Acorus comprises about 40 species, however, only a few species like Acorus calamus L. Acorus christophii, Acorus tatarinowii
(Schott.) and Acorus gramineus (Solandin Ait.) have been investigated for their chemical properties and their applications. Acorus calamus is extensively studied due to its medicinal and pharmacological significance (Ganjewala et al., 2011). Calamus oil is a brownish and yellow-coloured essential oil obtained from different parts of A. calamus. This oil contains several phytochemical constituent, but the major active constituent is the phenolic ether 'asarone' (upto 96\%). 
Acorus calamus is a native of Eastern countries and is indigenous to the marshes of the mountains of India. It is cultivated throughout India in the marshy tracts of Kashmir, Himachal Pradesh, Manipur, Nagahills and some parts of Karnataka state in peninsular India (Raja et al., 2009). It is a hardy plant found to grow in tropical and subtropical climates. The rhizomes of Acorus calamus possess antibacterial, bio pesticide and antifungal properties (Gaw, et al., 2002; Rani et al., 2003 and Parab et al., 2002).

The essential oil from the rhizomes is also used in the production of beer and alcoholic beverages such as bitters, cordials, vermouths and at lower level in foods such as frozen desserts, yoghurts, cakes and confectionery (Raina et al., 2003).

Normally, only the oil of the diploid variety is used for flavouring aromatic alcoholic beverages. The roots and rhizomes of Acorus calamus have been used in the ayurvedic system of medicine for treating a variety of diseases such as epilepsy add hysteria (Madan et al., 1960). The rhizome and leaf produce a light brown to brownish yellow volatile aromatic oil known as calamus oil. The yield of oil from different parts of the plant is upto $1.8 \%$ in fresh rhizome, 1.5 to $3.5 \%$ in dried rhizome (Chopra et al., 1986).

There are numerous methods for extraction of sweet flag rhizome oil. It can be extracted by solvent extraction using ethyl acetate as a solvent (Devi et al., 2013), steam distillation (Malik et al., 2014), Soxhlet extraction (Muthulakshmi et al., 2015) and also by super critical fluid extraction (Bruno et al., 2005). The oil contains many different compounds, in which $\beta$-asarone is the major compound.

The $\beta$-asarone (cis-2, 4, 5-trimethoxy-1propenylbenzene) is a sesquiterpenoid, is a major active principle found in oil of the rhizomes, along with a few fatty acids, terpenoids and flavonoids. The component $\beta$ asarone obtained from sweet flag rhizome has antimicrobial, insecticidal and pesticidal properties (Balakumbahan et al., 2010).

In view of this applications the present study is designed for the extraction of oil from the rhizome by supercritical fluid extraction method, $\beta$-asarone content in the extracted oil and its impact on the pulse beetles (Callosobruchus maculatus).

\section{Materials and Methods}

\section{Plant material}

The rhizome of the Acorus calamus L. was procured from the local market of Raichur, Karnataka (India). The dried rhizome was made powder by using water cooled pulverizer and sieved with $500 \mu$ mesh $(0.5$ $\mathrm{mm}$ ). The chemicals, reagents (analytical and HPLC grade) and pure standard of $\beta$-asarone were obtained from M/s. Himedia Chemical Co., Bengaluru.

\section{Supercritical fluid/ supercritical carbon dioxide $\left(\mathrm{SC}-\mathrm{CO}_{2}\right)$ extraction}

Sweet flag rhizome oil is extracted and carried out by supercritical fluid extraction method at different pressure as describes by (100, 150 and 200 bar) and temperature (45, 55 and $65^{\circ} \mathrm{C}$ ) at constant dynamic extraction time of $120 \mathrm{~min}$.

\section{Extraction yield}

The extraction yield of rhizome oil was calculated as per the method described by Marongiu et al., (2005). The extract from the $\mathrm{SC}-\mathrm{CO}_{2}$ was collected and the residue of the co-solvent from the extract was removed by using a rotary flash vacuum evaporator. The extract was then dried in the oven at $40{ }^{\circ} \mathrm{C}$ for 30 min. The extraction yield was computed by using the following expression. 
Extraction yield $(\%)=\frac{\mathrm{M}_{\text {extract }}}{\mathrm{m}_{\text {feed }}} \times 100$

Where,

$\mathrm{M}_{\text {extract }}=$ Mass crude extract, $\mathrm{g}$

$\mathrm{m}_{\text {feed }}=$ Feed mass, $\mathrm{g}$

\section{Extraction efficiency}

The extraction efficiency was calculated as per the method described by Olawale et al., (2012). Extraction efficiency (oil recovery) is the quantity (\%) of oil present in extract residue per $100 \mathrm{~g}$ of sweet flag rhizome powder. The extraction efficiency was calculated by using the following expression

Extraction efficiency $(\%)=\frac{\text { Quantity of oil recovered after extraction }}{\text { Known quantity of oil in sweet flag rhizome powder }} \times 100$

\section{Quantitative analysis of $\beta$-asarone by HPLC method}

$\beta$-asarone analysis of sweet flag rhizome oil is carried out by using HPLC (Shimadzu Series LC-10A system Kyoto, Japan) consisting of a liquid chromatography connected to a UVVIS detector $(10 \mathrm{~A})$, binary pump and controlled by Shimadzu class VP workstation software. The $\mathrm{C}_{18}$ column has been $(15 \times 4.6$ $\mathrm{mm}, 5.0 \mu \mathrm{m})$ and UV detector $(210 \mathrm{~nm})$. The flow rate was $1 \mathrm{ml} / \mathrm{min}$ and mobile phase consisted of water with $0.1 \%$ trifluoro-acetic acid (TFA) (solvent A) and methanol (solvent $B)$. The instrument was run in isocratic mode (A: 35; B: 65).

The detection was monitored at $210 \mathrm{~nm}$. The $\beta$-asarone compound from the $\mathrm{SC}-\mathrm{CO}_{2}$ extracted sweet flag rhizome oil was identified by comparing the retention times of chromatographic peaks using Quadra pole detector with NIST Library to relative retention indices (Shailajan et al., 2015; Avadhani et al., 2013).
Effect of sweet flag rhizome oil against pulse beetles (Callosobruchus maculatus)

The pulse beetles were collected from Department of Entomology, University of Agricultural Sciences, Raichur. Acetone was used as a solvent to disperse the sweet flag rhizome oil.

Plastic jars of $1000 \mathrm{ml}$ capacity were used as exposure chamber. Red gram grains (150 g) were taken for each treatment.

Twenty pulse beetles adults were placed in each glass jar. These adults were exposed to different dosage of sweet flag rhizome oil.

The doses of sweet flag rhizome oil were 10, 20, 30, 40, 50, 60 and $70 \mu \mathrm{l}$. All treatments were maintained triplicate for greater accuracy with there was one untreated control.

Application of sweet flag rhizome oil was carried out by releasing the required volume of appropriate oil solution from an automatic pipette to $(8 \mathrm{~cm}$ ) filter paper disk (Whatman No.2) attached to inner surface of the lid of the glass jars. Exposure periods for each treatment were 3,5 and 7 days. At the end of exposure period, jars were opened and beetles were separated from the grains and mortality was assessed (Mansoor et al., 2006).

\section{Statistical design}

Statistical analyses were carried out to study the effect of different parameters on all the dependent variables by Design-Expert software version 7.7.0 (Statease Inc., Minneapolis, USA). Factorial Completely Randomized Design (FCRD) using the statistical software AGRESS and the insecticidal activity of extracted oil was analysed by Completely Randomized Design (CRD) using statistical package. 


\section{Results and Discussion}

\section{Extraction yield and extraction efficiency}

The extraction yield of sweet flag rhizome oil obtained at different $\mathrm{SC}-\mathrm{CO}_{2}$ temperature and pressure combinations. The extraction yield and extraction efficiency varied in the range of 0.73 to $3.15 \mathrm{~g} / 100 \mathrm{~g}$ and 20.79 to $90.08 \%$. The interaction effect between treatment combinations are significant $(\mathrm{p}<0.01)$ at one percent level (Fig. 1).

From this results it is clear that as pressure increased from 100 to $200 \mathrm{bar}$, the extraction yield increased. This might be due to the fact that the increase in pressure increased the density of the $\mathrm{CO}_{2}$ there by increasing the solvent strength and solubility of the oil in $\mathrm{CO}_{2}$ (Yao et al., 2012). The highest extraction yield of $3.15 \mathrm{~g} / 100 \mathrm{~g}$ was recorded at $\mathrm{SC}-\mathrm{CO}_{2}$ pressure of 200 bar, temperature of $45{ }^{\circ} \mathrm{C}$ which was considered as the optimum and the best $\mathrm{SC}-\mathrm{CO}_{2}$ extraction condition for obtaining the highest oil yield from sweet flag rhizome powder. Results are in agreement with the earlier findings of (Yao et al., 2012), who reported optimal oil yield of $4.12 \mathrm{~g} / 100 \mathrm{~g}$ at a pressure of $35 \mathrm{MPa}$ and temperature of 55 ${ }^{\circ} \mathrm{C}$.

Similarly the variation of temperature during the supercritical fluid extraction (SFE) affects the density and the volatility of the analytes from the matrix. By increasing the temperature, the volatilities of the analytes increases but the supercritical $\mathrm{CO}_{2}$ density decreases (Ghasemi et al., 2006).

From figure 2, the pressure increased from 100 to 200 bar, the extraction efficiency increased. The highest extraction efficiency of $90.08 \%$ was recorded at $\mathrm{SC}-\mathrm{CO}_{2}$ pressure of $200 \mathrm{bar}$, and temperature of $45{ }^{\circ} \mathrm{C}$ which was considered as the optimum and best $\mathrm{SC}-\mathrm{CO}_{2}$ extraction condition for obtaining the highest oil efficiency from sweet flag rhizome powder.

Fig.1 Effect of pressure and temperature on extraction yield of sweet flag rhizome oil

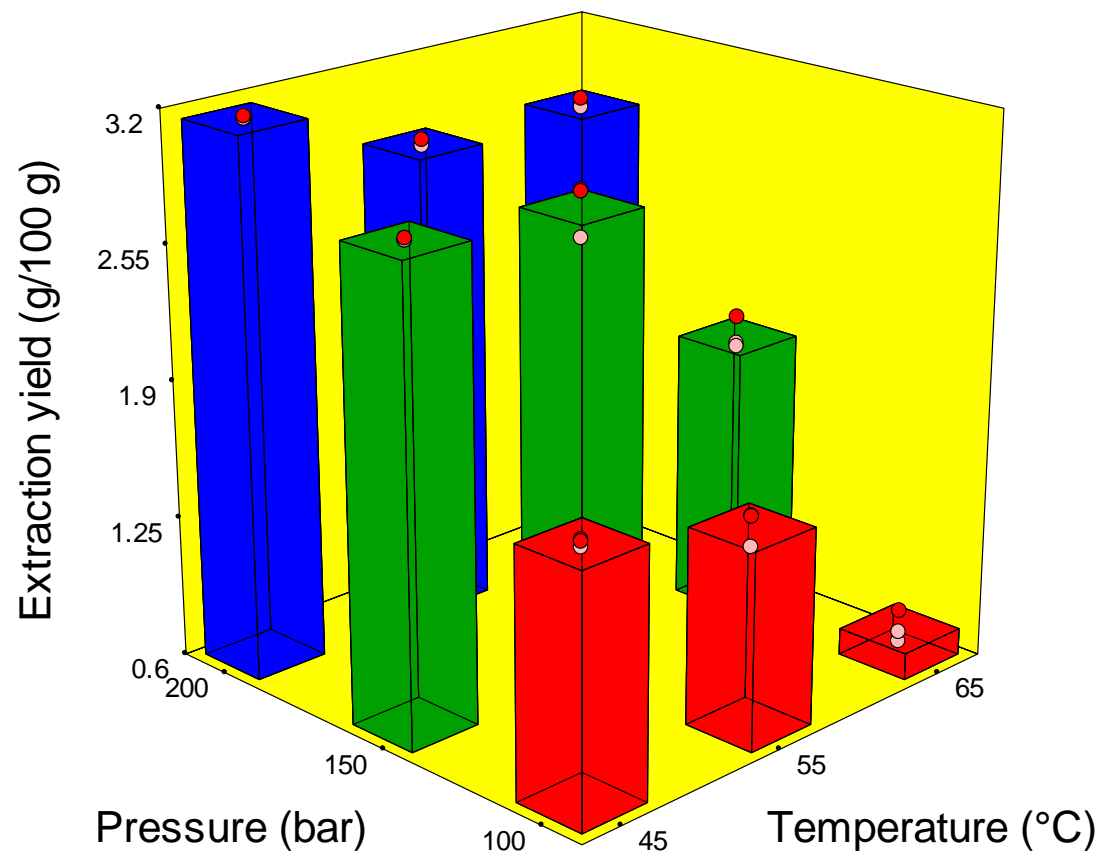


Fig.2 Effect of pressure and temperature on extraction efficiency of sweet flag rhizome oil

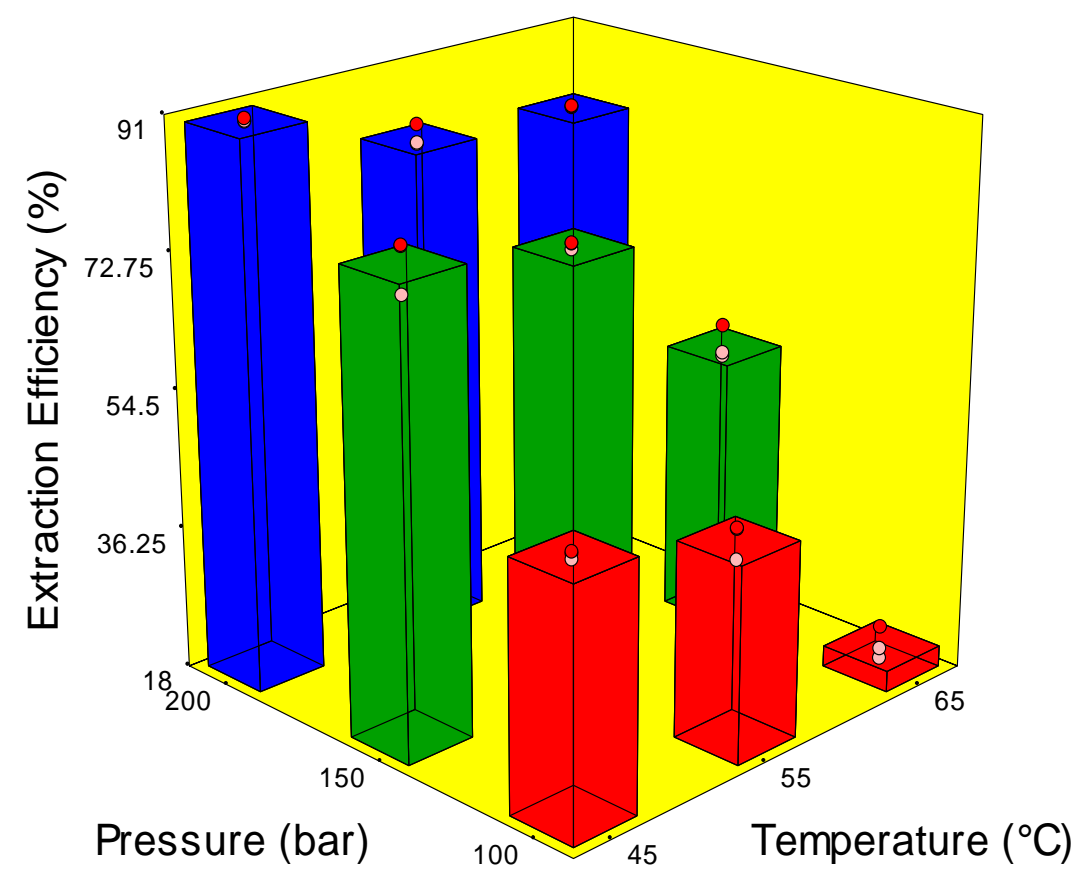

Fig.3 $\beta$-asarone content of extracted sweet flag rhizome oil

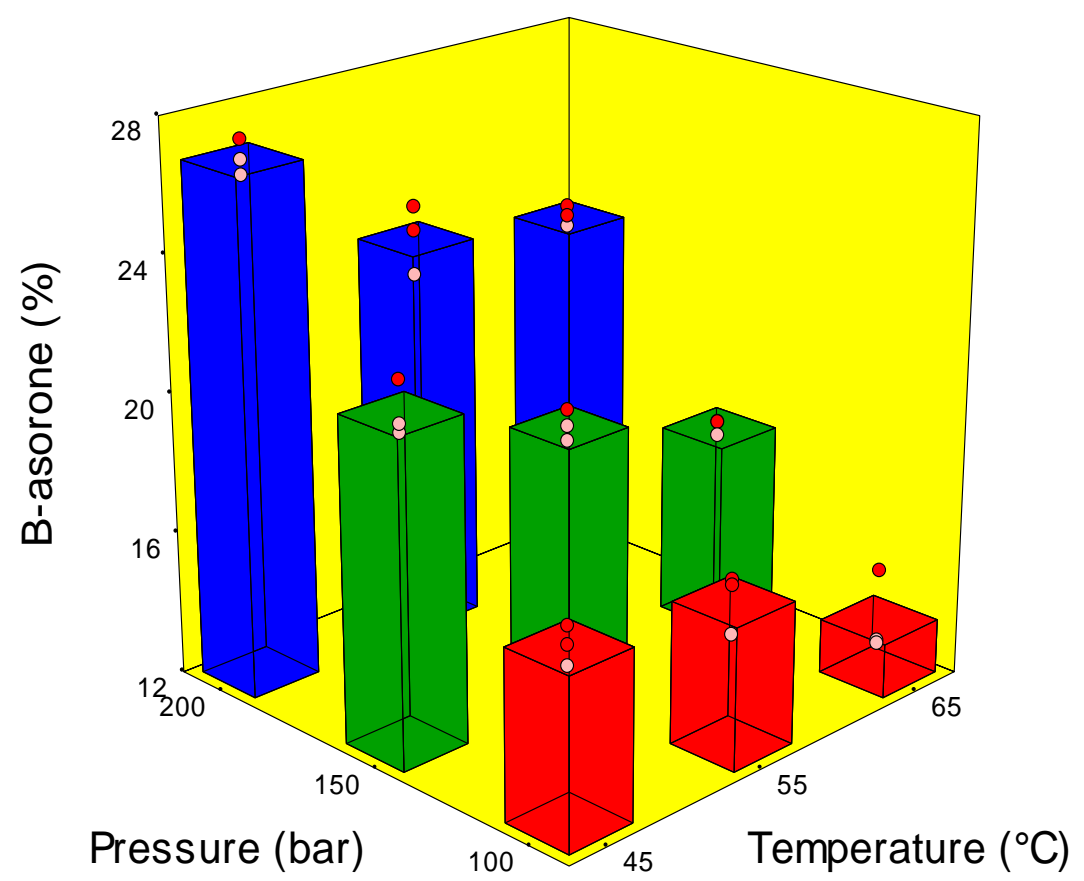


Fig.4 Effect of sweet flag rhizome oil on mortality of pulse beetles

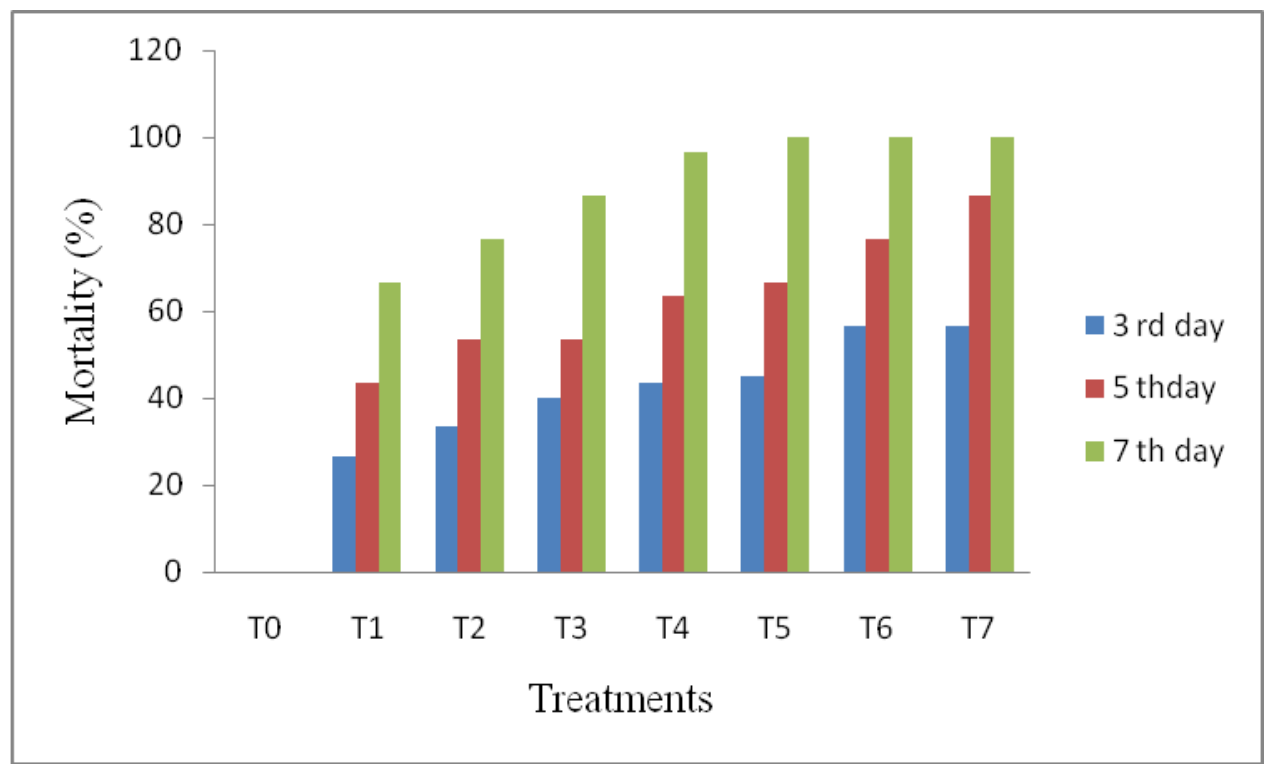

Quantitative analysis of $\beta$-asarone by HPLC method

The $\beta$-asarone content in sweet flag rhizome is mainly dependent on polidity level. The concentration of $\beta$-asarone was found to be from 13.58 to $26.80 \%$. The highest percentage of $\beta$-asarone was at 200 bar pressure and 45 ${ }^{\circ} \mathrm{C}$ temperature and the lowest percentage was found at 100 bar pressure and $65{ }^{\circ} \mathrm{C}$ temperature (Fig. 3).

$\beta$-asarone was further identified by comparing retention times with those of standard compounds. Similar results were reported by several other authors with different protocols for sample preparation and quantification of $\beta$-asarone in sweet flag rhizome oil (Avadhani et al., 2013).

Effect of sweet flag rhizome oil on mortality of pulse beetles (Callosobruchus maculatus)

The sweet flag rhizome oil with 10 to 70 $\mu \mathrm{l} / \mathrm{ml}$ concentration was tested. It was observed that highest mortality of pulse beetles were in treatment $T_{7}(70 \mu \mathrm{l} / \mathrm{ml})$, which recorded $70.38 \%$ mortality followed by $\mathrm{T}_{6}$ and $\mathrm{T}_{5}$ and lowest mortality was observed in treatment $T_{0}$ and $T_{1}$. Mortality was increased with increase in dose of oil and exposure time. The $T_{7}$ values were on par with the treatment $T_{6}, T_{5}$, and $T_{4} . T_{5}$ is the optimum dosage for the control of pulse beetles (Fig. 4) to manage the pulse beetles in storage of food grains.

Similar results were reported by Mansoor et al., (2006) who studied the insecticidal activity of different doses of Acorus calamus oil against Trogoderma granarium (Everts).

SC- $\mathrm{CO}_{2}$ extracted sweet flag rhizome oil yield $(3.15 \%)$ and extraction efficiency $(90.08 \%)$ at 200 bar pressure at $45{ }^{\circ} \mathrm{C}$.

The extraction yield and efficiency was decreased with increase in extraction temperature and increased with increase in the pressure. The $\beta$-asarone content was highest at 200 bar pressure at $45^{\circ} \mathrm{C}$.

The insecticidal activity of extracted sweet flag rhizome oil on pulse beetle was increased with dosages and exposure time. 


\section{Acknowledgement}

All the authors acknowledge their heartfelt gratitude to UAS, Raichur for the financial support extended for conducting the present investigation.

\section{References}

Avadhani, M. M. N., Selvaraj, I. C., Rajasekharan, P. E., Rajasekaran, C., Tharachand, C., Rao, V. K., Munirajappa, H., 2013. Asarone content and cytogenetic studies of medicinally important Indian Acorus calamus L., Accessions. Int. J. Pharm. Sci. Rev. Res., 22(2): 73-78.

Balakumbahan, P., Rajamani, K. and Kumanan, K., 2010. An overview of Acorus calamus. J. Med. Plants Res., 4(25): 2740-2745.

Bruno, M., Alessandra, P., Silvia, P. and Andrea, S., 2005. Chemical composition of the essential oil and supercritical $\mathrm{Co}_{2} \quad$ extract of Commiphoramyrrha (Nees) Engl. of Acorus calamus. J. Agri. Food Chem., 53(20): 7939-7943.

Chopra, R. N., Chopra, I. C. and Nayak, S. L., 1986. In: Glossary of Indian Medicinal Plants. Council of Industrial Research, New Delhi, 5.

Devi, A., Subhasini and Babu, S., 2013. Purification of beta asarone from Acorus calamus.L. Res. J. Pharm. Biol. and Chem. Sci., 4(4): 1279-1284.

Ganjewala, D., and Srivastava, A. K., 2011. An update on chemical composition and bioactivities of Acorus species. Asian J. Plant Sci., 1-8.

Gaw, M. C., Jager, A. K. and Staden, J. V., 2002. Isolation of $\beta$ - asarone an antibacterial and anthelmintic compound from Acours calamus in South Africa. S. Afr. J. Bot., 68(1): 3135.
Ghasemi, E., Yamini, Y., Bahramifar, N., and Sefidkon, F., 2006. Comparative analysis of the oil and supercritical $\mathrm{CO}_{2}$ extract of Artemisia sieberi. J. Food Engg, 79: 306-311.

Kazazi, H., Rezaei, K., Ghotb-Sharif, S. J., Djomeh, Z. E. and Yamini, Y., 2007. Supercritical fluid extraction of flavours and fragrances from Hyssopus officinalis L. cultivated in Iran. Food Chem., 105: 805-811.

Madan, B. R., Arora, R. B. and Kapila, K., 1960. Anticonvulsant, antiveratrinic and antiarrhythmic actions of Acorus calamus-an Indian indigenous drug. Archives Internationales de Pharmacodynamie et de Therapie 124: 201-211.

Malik, A., Ajhar, K. and Ahmad, N., 2014. Comparative study of HPTLC fingerprint of $\beta$-asaone content between leaves and rhizome of Acorus calamus. Int. J.Phar. Tech. Res., 6(2): 829-833.

Mansoor, H., Sagheer, M., Ullah, E., Ahmad, F. and Wakil, W., 2006. Insecticidal activity of different doses of Acorus calamus oil against Trogoderma granarium (everts). Pak. J. Agri. sci., 43(1-2): 2006.

Marongiu, Bruno, Piras, Alessandra, Porcedda, Silvia, Scorciapino, Andrea. 2005. "Chemical Composition of the Essential Oil and Supercritical CO2 Extract of Commiphora myrrha (Nees) Engl. and of Acorus calamus L.". J. Agri. Food Chem.53 (20): 7939-7943.

Muthulakshmi, T., Saleh, A. M., Kumara, N. V., Priya, K. M. and Palanichamy, V., 2015. Screening of phytochemicals and in vitro antioxidant activity of Acorus calamus. v. Int. J. Drug Dev. and Res., 7(1): 44-51.

Olawale, S. A., 2012. Solid-liquid extraction of oils of African elemi's (Canarium schweinfurthii's) fruit. J. Agric. Engg. Int:CIGR., 14(2): 155-172. 
Parab, R. S. and Mengi, S. A., 2002. Hypolipidemic activity of Acorus calamus L. in rats. Fitoterapia 73(6): 451-455.

Raina, V. K., Srivastava, S. K. and Syamasunder, K. V., 2003. Essential oil composition of Acorus calamus $L$. from the lower region of the Himalayas. Flavour Fragr. J., 18(1): 18-20.

Raja, A. E., Vijayalakshmi, M. and Devalarao, G., 2009. Acorus calamus Linn: chemistry and biology. Res. J. Pharm. and Tech., 2(2): 256261.

Rani, A. S., Satyakala, M., Devi, V. S., and Murty, U. S., 2003. Evaluation of antibacterial activity from rhizome extract of Acorus calamus Linn. J. Sci. Ind. Res., 62: 623-625.

Rasool, A., Ahmad, F., Hassan, M. and Ahmad, M. S., 2002. Insecticidal activity of different doses of
Acaruscalamus L. oil against Tribaliumcastaneum (Hbst.) (Coleptera: Tenebrionidae). Pak. Entomol., 24(1): 49-52.

Shailajan, S., Menon, S., Swar, G., Singh, D., and Nair, S., 2015. Estimation and quantitation of $\beta$-asarone from Acorus calamus rhizome and its formulations using validated RP-HPLC method. Pharm. Methods, 6(2): 94-99.

Yao, Y., Cai, W., Yang, C. and Hua, H., 2012. Supercritical fluid $\mathrm{Co}_{2}$ extraction of Acorus calamus L. (Arales: Araceae) and its contact toxicity to Sitophilus zeamais Motaschusky (coleopteran: curculioniodae). Nat. Prod. Res. 26(16): 1498-1503.

Zaidi, S. R., Jilani, G., Ashfaque, M., Iqbal, J., and Rafeeq, U., 2003. Oviposition response of Sitatroga cerealella (Oliv.) to plant extracts. Pak. Entomol., 25(2): 183-189.

\section{How to cite this article:}

Shreelaxmi, H. Sharanagouda, C.T. Ramachandra, R.S. Roopa and Hanchinal, S.G. 2017. Supercritical Fluid Extraction of Oil from Sweet Flag Rhizome (Acorus calamus L.) and Its Insecticidal Activity on Pulse Beetles (Callosobruchus maculatus). Int.J.Curr.Microbiol.App.Sci. 6(10): 3608-3615. doi: https://doi.org/10.20546/ijcmas.2017.610.425 